$$
\text { Health Policy Report }
$$

\section{WHAT'S HAPPENING TO BRITAIN'S National Health Service?}

\author{
RUdOLF KLEIN
}

$\mathrm{B}$ RITAIN'S National Health Service (NHS), as constituted in 1948, had two defining characteristics. First, it was a universal system, funded predominantly by taxation, that made health care available to the whole population and removed financial barriers to access. Second, it was essentially a paternalistic system designed to meet the needs of patients as defined by the professionals delivering the services rather than to respond to the demands articulated by patients. These have continued to be the defining characteristics of the NHS over the decades. Now, however, the government is proposing a transformation of the system. The financial and organizational framework of the NHS is to remain intact, but the dynamics will change. The NHS will cease to be "a 1940s system operating in a 2lst century world," as it was described last year in "The NHS Plan," a report setting out the government's policies. ${ }^{1}$ Waiting lists will no longer be the symbol of the NHS, and the system will no longer be dominated by providers. Instead, it will be a responsive, patient-centered system guaranteeing quick access to care that meets a uniform standard of high quality throughout the country.

That, at any rate, is the vision. To achieve it, the British government has pledged to increase funding for the NHS over the next few years at an unprecedented rate. Even so, the plan to transform the system remains a high-risk enterprise - the equivalent of reengineering a racing car while it is whizzing round the track - for the plan assumes nothing less than a change in the culture of the NHS, with important implications for the medical profession, among others. In this report, I discuss the specific policy initiatives that are being introduced and analyze their chances of success. In doing so, my focus is on the NHS in England. Wales and Scotland have been given greater scope to decide their own policies, and the health services in those countries are increasingly diverging from the model in England.

\section{RECENT HISTORY OF THE NHS}

Since the NHS was instituted, successive governments have strived to reconcile two objectives: min-

From the London School of Economics and the London School of Hygiene and Tropical Medicine - both in London. imizing its budget while maximizing its productivity. ${ }^{2}$ The first objective reflects the fact that health care has to compete with other services (such as education) for public resources and is further constrained by the desire of all governments to win elections by keeping taxes as low as possible. The second objective reflects the fact that a combination of demographic changes and technological advances has made it imperative to increase the NHS's output of services if public expectations are to be met.

The first objective has been achieved. The NHS remains a model of fiscal restraint. It provides a universal service at a lower cost - as measured by the proportion of the national income devoted to health care - than that of health care systems in similar countries. But maximizing productivity - the second objective - has led to a continuous effort by successive governments to squeeze more services out of the available resources. And, to an extent, the strategy has succeeded. As measured by the number of patients treated and the number of procedures carried out, the NHS has an impressive record of improving efficiency year by year.

There was a price to be paid, however. Strengthening management, one of the strategies adopted, may have helped increase efficiency. But it also created resentment among health care professionals - in particular, doctors - who saw it as a threat to their status and autonomy. And resentment led to protest. By the end of the 1980s, the medical profession was proclaiming (not for the first time) the impending collapse of the NHS. Doctors became less and less inclined to accept responsibility for having to ration scarce resources by presenting decisions about whom to treat and how as clinical decisions. ${ }^{3,4}$ The political costs to the government of economic stringency began to rise. Ministers might spout statistics about the number of patients treated and the number of operations carried out, but the public preferred to believe the doctors and nurses who appeared on television to grumble about inadequacies. Complaints about the underfunding of the NHS - a constant theme almost since the start of the system - rose in pitch and volume.

In 1991, in response to these problems, Margaret Thatcher's government introduced the so-called internal market. Previously, health authorities, funded by the national government, had been responsible for running hospitals and other services. Now they became purchasers, buying health care from semiindependent hospital trusts. At the same time, the government introduced fundholding for general practitioners. Previously, general practitioners had referred patients to specialists and had had no incentive to take into account the costs of specialty care. With the new approach, general practitioners could opt to have budgets for purchasing the specialty services their patients needed. The underlying assumption was that 
competition among providers and increased sensitivity to price among purchasers would lead to greater efficiency.

For a variety of reasons, the internal market never worked as intended, ${ }^{5,6}$ though there is some evidence of improved efficiency. But it did have some unforeseen consequences. It reinforced resentment within the medical profession, which had demonstrated its impotence by campaigning strenuously but unsuccessfully against the reforms. The internal market also increased the visibility of the NHS's activities (and failings) by generating more information about the service, an effect compounded by the increasing interest of the media in the system. At the 1997 general election, which brought Tony Blair's Labour Party into office, the NHS was one of the liabilities of the incumbent Conservative Party.

\section{THE NEW LABOUR PARTY}

The Labour Party came into power pledging to abolish the internal market. And in rhetoric it did so within a few months. The 1997 report spelling out the Labour government's plans for the $\mathrm{NHS}^{7}$ announced the abolition of the internal market. Cooperation was to take the place of competition. But the separation of functions between purchasers and providers remained. Similarly, fundholding by general practitioners was abolished. However, it was replaced by primary care groups, with delegated budgets. These groups consisted of general practitioners in geographically defined areas (average population, 100,000) who were responsible for purchasing health care on behalf of their patients. The primary care groups are evolving into primary care trusts, with independent budgets, and by 2004 they will be responsible for spending some 75 percent of the NHS's budget. In effect, fundholding has become universalized. General practitioners, in the words of the 1997 report, "will be in the driving seat in shaping local health services in the future."

This could signal perhaps the most radical change in the history of the NHS: a service driven from the bottom up instead of from the top down, reflecting local rather than national priorities. But it is far from clear how much freedom the primary care trusts will have in "shaping local health services," since the 1997 report also announced a battery of measures designed to strengthen the grip of the central government on the service. These measures reflected the government's commitment to creating a service that offers uniformly high standards of care throughout the country. This had been the ambition of the NHS's founders. But in practice it had not been achieved: geographic variations in the scope, efficiency, and quality of services persisted. For example, rates of hip replacement for persons over the age of 65 years ranged from 1.5 per 1000 population in Doncaster to more than 4 per 1000 in Devon. Similarly, some hospitals performed almost 100 percent of cataract-removal operations as day surgery, whereas others carried out less than 10 percent on an outpatient basis.

To achieve its aims, the government launched a variety of new initiatives. It introduced a system of clinical governance: every trust was required to establish a means of reviewing the quality of the services it provided. The government also created a national inspectorate, the Commission for Health Improvement, to ensure that this system of quality control was working effectively. The National Institute for Clinical Excellence was established "to promote clinical and cost-effectiveness by producing clinical guidelines and audits, for dissemination throughout the NHS." National Service Frameworks for cancer and other major areas of care were introduced as blueprints for the design of local services. The government established a host of new indicators in order to assess the performance of individual providers. ${ }^{8}$ These included indicators of efficiency (such as the cost per unit of service), appropriateness (such as rates of dilation and curettage performed in women under the age of 40 years and rates of surgery for otitis media), and outcomes (such as preventable diseases and adverse events).

It remains to be seen whether this emphasis on quality will limit the autonomy of clinicians and, if so, in what ways. Contrary to the view that "socialized medicine" means less freedom for doctors, clinicians in the NHS have traditionally enjoyed much greater immunity from scrutiny than have their counterparts in the United States. Now, however, this is changing. It is still uncertain, for example, whether the guidelines of the National Institute for Clinical Excellence on what drugs to prescribe and what procedures to perform will be mandatory or whether they will change clinical practice. But it is clear that the medical profession is under pressure to eradicate poor practice. Following a series of scandals involving individual clinicians and under pressure from the government, the General Medical Council (the body responsible for licensing and disciplining doctors) is reforming its procedures and constitution. ${ }^{9}$ It is also introducing regular revalidation reviews for all doctors - that is, doctors will be required to demonstrate their continued competence to practice. In short, the council is attempting to protect the collective autonomy of the profession by limiting the autonomy of its individual members. And the government is introducing procedures for assessing doctors whose performance is considered inadequate by their employers in the NHS. ${ }^{10}$

The effect of these initiatives on patients has been less apparent. The one visible change was the introduction of NHS Direct, a telephone advisory service operated by nurses. Overall, the immediate effect was to raise public expectations without satisfying them, since the government had not provided the 
additional resources required to do so. Waiting lists for surgery, tests and other procedures, and appointments continued to remain long, and a succession of initiatives designed to shorten the lists were only marginally effective. Evidence of inadequacy continued to accumulate, particularly in the winter of 1999 , when an outbreak of influenza overloaded emergency departments.

The government's reaction was to intervene more directly and frantically in the affairs of the NHS. Managers and health care professionals struggled to remain afloat in a sea of performance targets and instructions sent to them by the central administration. Morale in the NHS slumped. Increasing centralization meant the concentration of blame on the government.

\section{MORE MONEY AND MORE PLANS}

With the NHS threatening to become an electoral liability for the Labour Party, the government abandoned its commitment to fiscal restraint. On January 16, 2000, Prime Minister Tony Blair announced a large increase in resources for the NHS, in effect conceding that the service had indeed been underfunded. The aim was to raise the level of expenditures for the NHS from 6.7 percent of the gross domestic product to 8 percent - the average level in the European Union - by 2006 (as compared with 14 percent in the United States). And the government followed up Blair's announcement by issuing "The NHS Plan," which explained how the extra money was to be spent.

"The NHS Plan" set out an ambitious program of expansion over the coming five years. It promised 7000 additional hospital beds, 7500 more specialists, 2000 more general practitioners, 20,000 more nurses, and 6500 more therapists. The expectation was that with these extra resources, all patients who wanted to see their general practitioners would have appointments within 48 hours; that the maximal waiting times for a hospital appointment and for inpatient treatment would be cut to three and six months, respectively; that hospital wards would be cleaner and hospital food improved; and that there would be an expansion of various screening programs. These are only some of the promised improvements, but they illustrate the extent and nature of the acknowledged shortcomings of the NHS.

According to "The NHS Plan," the modernized NHS is to be centered on patients. There will be new performance incentives for health care professionals and greater flexibility in their roles. Patients will be "empowered" by being given more information. Furthermore, a patients' forum is to be set up in every primary care trust to articulate views about how local services should be run. Lastly, to underline the New Labour Party's radicalism, there will be more cooperation with, and use of, the private sector - an ap- proach that the Labour Party had previously never been willing to contemplate.

\section{FUTURE PROSPECTS}

The strategy of the Labour government represents a gamble. First, it represents a race against time. Will it be possible to recruit and train the additional staff on schedule? Can the culture of an organization as complex and as rooted in tradition as the NHS be transformed within five years? Second, everything hinges on the continued prosperity of the British economy. The history of the NHS is littered with plans for increased spending that had to be abandoned because of economic squalls. Third, will there be sufficient visible improvements in performance to satisfy public expectations? Fourth, the government's calculation is that the British people want faster access to improved facilities rather than the freedom to choose providers. Thus, the primary care trusts will remain geographic monopolists with, in effect, a captive population. Individual practices within the trusts also tend to be geographic monopolists, so that in fact, patients often cannot exercise their right to choose a general practitioner. Can the service be made more responsive to patients' demands by strengthening the voice of patients rather than by providing them with opportunities to seek care elsewhere?

The last and perhaps most important question is whether the government can enlist the medical profession in its efforts to reform the NHS. Neither the promise of extra resources nor the other measures have halted the decline in the profession's morale. On the contrary, discontent has continued to mount among both general practitioners ${ }^{11}$ and specialists. ${ }^{12}$ In part, this reflects international trends and is not specific to Britain. Apprehension about threats to medical autonomy and about changing patterns of practice is widespread. Witness the backlash against managed care in the United States and the recent doctors' strikes in Canada and the Netherlands. But plummeting morale among British physicians also reflects the fact that national policies are imposing extra demands on them, and the prospect of relief from this pressure is only a promissory note. Without the active engagement of the medical profession, the government is unlikely to achieve its goals.

If the gamble does not pay off, the prospect is that the present set of reforms will not be the last. In the general election of June 2001, which once again resulted in a large Labour majority, the government made improvements in public services such as the NHS a central part of its program. And although "The NHS Plan" makes a rhetorical commitment to decentralization, the national government may become increasingly zealous and intrusive in its efforts to satisfy the public expectations that it has stoked up - and in doing so, the government may paradoxically underline its responsibility for any failings. 
If so, the political costs of maintaining the NHS in its present form will escalate.

\section{REFERENCES}

1. Secretary of State for Health. The NHS Plan. London: Her Majesty's Stationery Office, 2000

2. Klein R. The new politics of the National Health Service. 4th ed. Harlow, England: Prentice-Hall, 2000.

3. Aaron HJ, Schwartz WB. The painful prescription: rationing hospital care. Washington, D.C.: Brookings Institution, 1984.

4. Klein R, Day P, Redmayne S. Managing scarcity: priority setting and rationing in the National Health Service. Buckingham, England: Open University Press, 1996.

5. Le Grand J, Mays N, Mulligan J-A, eds. Learning from the NHS internal market: a review of the evidence. London: King's Fund, 1998.
6. Enthoven AC. In pursuit of an improving National Health Service. London: Nuffield Trust, 1999

7. Secretary of State for Health. The new NHS: modern-dependable.

London: Her Majesty's Stationery Office, 1997.

8. NHS Executive. A national framework for assessing performance.

London: Department of Health, 1998.

9. Protecting patients: a summary consultative document. London: General Medical Council, March 2001.

10. NHS Executive. Assuring the quality of medical practice. London: Department of Health, January 2001.

11. Beecham L. Most GPs would consider resigning from NHS. BM] 2001;322:1381

12. Idem. Senior hospital doctors issue warning to new government. BMJ 2001;322:1381.

Copyright $\odot 2001$ Massachusetts Medical Society.

\section{FULL TEXT OF ALL JOURNAL ARTICLES ON THE WORLD WIDE WEB}

Access to the complete text of the Journal on the Internet is free to all subscribers. To use this Web site, subscribers should go to the Journal's home page (http://www.nejm.org) and register by entering their names and subscriber numbers as they appear on their mailing labels. After this one-time registration, subscribers can use their passwords to log on for electronic access to the entire Journal from any computer that is connected to the Internet. Features include a library of all issues since January 1993 and abstracts since January 1975, a full-text search capacity, and a personal archive for saving articles and search results of interest. All articles can be printed in a format that is virtually identical to that of the typeset pages. Beginning six months after publication the full text of all original articles and special articles is available free to nonsubscribers who have completed a brief registration. 